\title{
Validity of a Manual Soft Tissue Profile Prediction Method Following Mandibular Setback Osteotomy
}

Olga - Elpis Kolokithaa, DDS, MSD, Dr Dent

\section{ABSTRACT}

Objectives: The aim of this study was to determine the validity of a manual cephalometric method used for predicting the post-operative soft tissue profiles of patients who underwent mandibular setback surgery and compare it to a computerized cephalometric prediction method (Dentofacial Planner). Lateral cephalograms of 18 adults with mandibular prognathism taken at the end of presurgical orthodontics and approximately one year after surgery were used.

Methods: To test the validity of the manual method the prediction tracings were compared to the actual post-operative tracings. The Dentofacial Planner software was used to develop the computerized post-surgical prediction tracings. Both manual and computerized prediction printouts were analyzed by using the cephalometric system PORDIOS. Statistical analysis was performed by means of t-test.

Results: Comparison between manual prediction tracings and the actual post-operative profile showed that the manual method results in more convex soft tissue profiles; the upper lip was found in a more prominent position, upper lip thickness was increased and, the mandible and lower lip were found in a less posterior position than that of the actual profiles. Comparison between computerized and manual prediction methods showed that in the manual method upper lip thickness was increased, the upper lip was found in a more anterior position and the lower anterior facial height was increased as compared to the computerized prediction method.

Conclusions: Cephalometric simulation of post-operative soft tissue profile following orthodonticsurgical management of mandibular prognathism imposes certain limitations related to the methods implied. However, both manual and computerized prediction methods remain a useful tool for patient communication. (Eur J Dent 2007;1:202-211)

Key words: Orthognathic surgery; Mandibular setback; Prediction; Cephalometry; Soft tissue profile.

a Department of Orthodontics, School of Dentistry, Aristotle University of Thessaloniki,

Thessaloniki, Greece.

Corresponding Author:

Olga - Elpis Kolokitha, DDS, MSD,

Dr Dent Lecturer Department of Orthodontics,

School of Dentistry Aristotle University of Thessaloniki

GR - 54124 Thessaloniki Greece

Tel.: +30 2310999556 Fax: +30 2310999549

E-mail: okolokadent.auth.gr

\section{INTRODUCTION}

Correction of dentofacial deformities often requires combined surgical orthodontic treatment in order to achieve optimal functional, aesthetic and psychosocial results. The clinical protocol involves prediction of both the surgical movements and soft tissue profile. Prediction should be accurate in order to assess treatment feasibility, optimize case management and increase patient understanding and acceptance of the recommended treatment. ${ }^{1}$ 
Many studies have evaluated soft tissue changes following orthognathic surgery and provide the clinician with an idea of the expected soft tissue changes. ${ }^{2-5}$ The predictability of soft tissue changes following orthognathic surgery is not a precise science. ${ }^{6}$ Cephalometric prediction can be done manually or by using the computer; several manual prediction methods have been suggested. ${ }^{7-10}$ The manual cephalometric prediction may be performed by moving templates for different dental structures or by using the overlay method. The computerized prediction uses several currently available software programs ${ }^{11-}$ ${ }^{18}$ alone, or in combination with video images ${ }^{19}$ to assess the treatment outcome.

Today, computerized cephalometric analysis systems are used in orthodontic and maxillofacial surgery practices for diagnostic and prognostic purposes, as well as for treatment plan evaluation of surgical - orthodontic treatment cases. ${ }^{20}$ Prediction of soft tissue profile changes in orthognathic patients is an important feature of these systems. Although their popularity has increased, they are not yet extensively used by orthodontists or maxillofacial surgeons and the conventional manual prediction method is still used.

The aim of this study was to determine the validity of a manual cephalometric method in predicting the soft tissue profiles of patients who underwent mandibular setback surgery. Thus, the manually predicted soft tissue profiles were compared to the actual post-surgical profiles. Comparison between the computerized cephalometric prediction and the actual post-operative profile was the object of a study published previously. ${ }^{21}$ Furthermore, the study also aimed at comparing the manual to a computerized (Dentofacial Planner) method of soft tissue profile prediction.

\section{MATERIALS AND METHODS}

Eighteen patients from the region of Jutland, Denmark who received bilateral vertical ramus osteotomy $^{22}$ for mandibular setback composed the sample of this study. Patient age at the time of surgery ranged from 17 to 39 years. Patients with craniofacial anomalies, clefts, syndromes and full dentures were excluded from the sample. Surgical treatment was performed by three surgeons of the Department of Oral and Maxillofacial Surgery at
Aarhus University, Denmark.

Maxillo-mandibular fixation was performed in all patients with duration varying from 6 to 8 weeks. A minimum-thickness wafer was interposed between the maxillary and mandibular arches during the fixation period to facilitate stability and positioning of the segments. All patients received pre- and post-surgical orthodontic treatment by means of fixed appliances.

Lateral cephalograms taken one week before surgery and approximately one year after the operation (mean time 11.4 months) were used. Post-surgical orthodontics was completed for all patients and fixed orthodontic appliances were removed at the time the second cephalogram was taken. All cephalograms used in this study were taken in the same cephalostat at the Department of Oral Radiology, Aarhus University in natural head position (mirror position), lips in repose and teeth in habitual occlusion ${ }^{23}$ with a calculated enlargement of midsagittal plane structures of $5.5 \%$.

Manual tracing and superimposition of cephalograms

The pre-operative and post-operative lateral cephalograms of each patient were traced on acetate paper. The objective was to estimate the exact amount and direction of maxillomandibular repositioning that took place after the operation. For this reason, a coordinate reference system consisting of horizontal and vertical planes into which all cephalometric landmarks could be located as $\mathrm{x}$ and $\mathrm{y}$ values was constructed (Figure

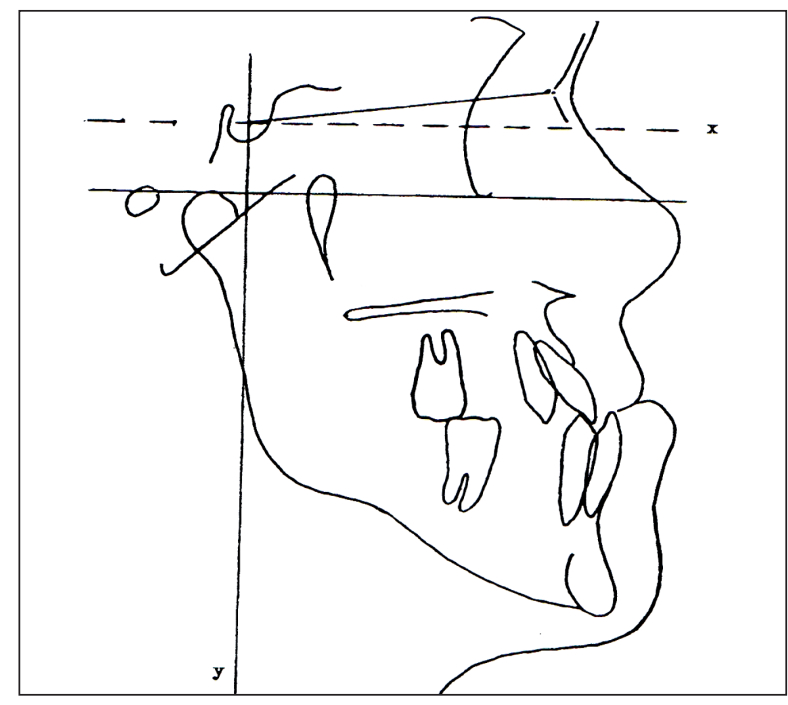

Figure 1. Coordinate system construction. 
1). A line parallel to the Frankfort Horizontal through Sella was used as the best estimate for the horizontal plane and a line perpendicular to this plane through Sella represented the vertical plane. Pre- and post-operative tracings of each patient were superimposed on $\mathrm{SN}$ and by means of the coordinate system aided by a millimetre grid the exact amount and direction of the actual operative jaw repositioning was assessed. Thus, the exact backward movement of mandibular incisors as a result of the surgical setback was also calculated in millimetres. The method used has already been described in a previous study. ${ }^{21}$

\section{Manual prediction of soft tissue changes}

Manual prediction of soft tissue changes following mandibular surgery was performed according to the overlay tracing method described by Proffit.24 The overlay tracing method is the simplest way to simulate the effects of mandibular surgery. A second acetate paper (overlay tracing) was placed over the original pre-surgical tracing to trace the structures that are not affected by mandibular osteotomies. The overlay tracing was held stable and the underlying pre-surgical tracing was moved backwards at a distance that equals the mandibular incisor surgical movement calculated as mentioned above. The mandible and lower teeth were traced at that position. According to the overlay method, backward lower lip movement equals $60 \%$ of the surgical incisor movement; thus, a point was drawn at the calculated distance on the overlay tracing reflecting lower lip position. The overlay and pre-surgical tracings were superimposed on the mandible and, through the point soft tissue chin and lower lip outline were drawn. By superimposing on the cranial base, the predicted soft tissue profile was completed using as a guide ratios that indicate the soft and hard tissue interplay after surgery. ${ }^{25}$ Thus, a tracing of the manually predicted soft tissue profile became available (manual prediction profile).

\section{Computerized prediction of soft tissue changes}

Pre-surgical cephalograms were digitized and processed by means of the Dentofacial Planner software; computerized post-surgical printouts were developed. ${ }^{21}$

\section{Tracing analysis}

Four profile tracings were available for each patient: pre-operative, computerized prediction, manual prediction and actual post-operative. All tracings were digitized and entered into the computerized cephalometric software system PORDIOS (Purpose On Request Digitizer InputOutput System, Institute of Orthodontic Computer Sciences, Aarhus, Denmark), which calculated all the cephalometric variables used in this study. In order to compare the computerized and manual prediction profiles and to test the prediction validity of the manual method (comparison between manually predicted and actual post-operative profiles) the author used the Profile Analysis cephalometric appraisal (included in the PORDIOS software), which incorporates variables from different well-known cephalometric analyses. ${ }^{26}$ Profile Analysis includes 30 landmarks and 59 linear and angular variables. ${ }^{27}$ For each patient, 30 cephalometric landmarks where identified on the computerized prediction, manual prediction and actual post-treatment profile tracings (Figure 2). Identification of landmarks, tracings,

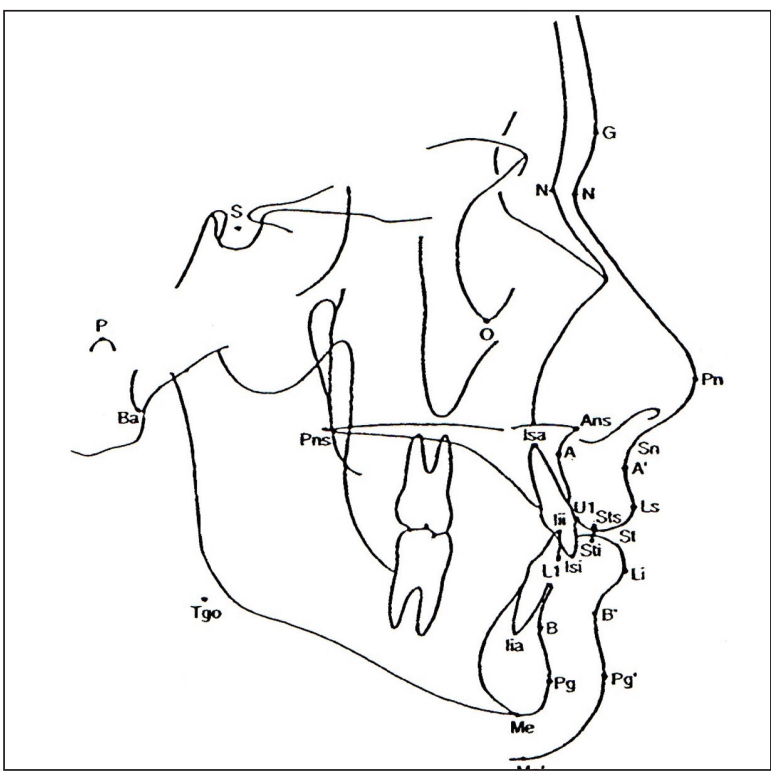

Figure 2. Dentoskeletal and soft tissue cephalometric landmarks used in the comparison of the prediction and posttreatment computer profile printouts. $\mathrm{G}=$ glabella; $\mathrm{S}=$ sella $\mathrm{N}=$ nasion; $\mathrm{N}^{\prime}=$ =soft tissue nasion; $\mathrm{P}=$ porion; $\mathrm{O}=$ orbital; $\mathrm{Ba}=$ basion $\mathrm{Pn}=$ pronasale; $\mathrm{Pns}=$ posterior nasal spine; Ans=anterior nasal spine; Isa=incision superior apical; $S n=$ subnasale; $A=$ point $A_{;} A^{\prime}=$ soft tissue point $A$; $U 1=$ maxillary incisor; Ls=labrale superius; lii=incision inferior incisal; $\mathrm{Sts}=$ stomion superius; Sti=stomion inferius; St=stomion; $L 1=$ mandibular incisor; Isi=incision superior incisal; Li=labrale inferius; Tgo=tangent gonion; $B=$ point $B$; $B^{\prime}=$ soft tissue point $B$; lia=incision inferior apical; $\mathrm{Pg}=$ pogonion; $\mathrm{Pg}^{\prime}=$ soft tissue pogonion; $\mathrm{Me}=$ menton; $M e^{\prime}=$ soft tissue menton 
superimpositions, digitizing of cephalograms and computer printouts were performed by the author.

Statistical analysis

Paired t-tests were used to determine any statistically significant differences $(P<.05)$ of cephalometric variables for both the computerized and manual soft tissue predictions; statistically significant differences between manually predicted and actual post-operative patient profile were also determined. Correction of type 1 error level was done by the Bonferroni method.

\section{Method error}

Eleven randomly selected manual prediction tracings were digitized twice. All 59 cephalometric variables of the Profile Analysis were compared by means of paired t-test. No statistically significant differences ( $P>$.05) were found for any of the variables. The error of superimposition was estimated by performing double superimposition and double measurements for all patients. All measurements were analyzed by means of the method error test. No statistically significant differences were found. The error of landmark displacement during computer simulation of jaw repositioning was estimated by using paired t-tests. No statistically significant differences $(P>$.05) were found. The error of landmark identification and, digitizing of Dentofacial Planner prediction printouts and post-treatment tracings was estimated by digitizing twice the Dentofacial Planner predictions and by calculating error magnitude for all cephalometric variables. No statistically significant differences were found for any of the variables.

\section{RESULTS}

Validity of manual prediction

Statistically significant differences between manual predictions and actual post-operative profiles are presented in Table 1. Statistically significant differences between manual prediction and actual profile were found only for the sagittal soft tissue cephalometric variables. Distances $\mathrm{N}^{\prime}-\mathrm{A}, \mathrm{N}^{\prime}$ - Ls and $\mathrm{N}^{\prime}$-St indicating upper lip position were found to be greater in the manual prediction, indicating a more prominent upper lip. Mandibular plane inclination (MPL/SN and MPL/FH) was significantly decreased in the manual predictions.
However, significant differences did not exist between manually predicted and actual profiles for both the skeletal and soft tissue total anterior facial height. The values of the manually predicted and the actual incisor relationship variables were not statistically significant $(P>.05)$. Upper lip thickness at point $A$ ( $A^{\prime}-A$ eff length) is increased in the manual prediction. Labrale inferior (Li/Pg'Ls) was found in a more anterior position relative to its actual position.

\section{Comparison between manual and} computerized predictions

Statistically significant differences between manual and computerized predictions are presented in Table 2. No statistically significant differences were found between manual and Dentofacial Planner surgical predictions concerning the sagittal skeletal cephalometric variables. With regard to the sagittal soft tissue cephalometric variables, the manual prediction overestimated the $\mathrm{N}^{\prime}-\mathrm{Pg} / \mathrm{Pg}^{\prime}-\mathrm{Ls}^{\prime}$ angle and $\mathrm{N}^{\prime}$-Ls distance that represents the position of the upper lip. Skeletal lower anterior facial height (ANS$\mathrm{Mel}$ was statistically significantly increased in the manual prediction as compared to the Dentofacial Planner prediction. This change increases the total anterior skeletal height $(\mathrm{N}-\mathrm{Me})$ of the manual prediction. None of the vertical soft tissue cephalometric variables showed any statistically significant differences between manual and Dentofacial Planner predictions. No statistically significant differences were found for the cephalometric variables associated with incisor relationships. Upper lip thickness at subnasale (Sn-A eff) and at incisor level (Ls-Uifac eff) was increased in the manual prediction as compared to the Dentofacial Planner prediction. There were no statistically significant differences in any of the variables, but the distance $A^{\prime}$ - Ls. The upper lip ( $A^{\prime}$ Ls) was in a more anterior position in the manual as compared to the computerized prediction.

\section{DISCUSSION}

Validity of manual prediction

Validity, or accuracy, is the extent of value obtained represents the object of interest, in absence of measurement error. ${ }^{28}$ Accurate prediction of the post-operative facial profile is an essential step in treatment planning of combined 
Table 1. Mean value differences between manual prediction (M) and actual profile (AP) printout tracings $(M-A P)(n=18)$.

\begin{tabular}{|c|c|c|}
\hline Variables & $X(M-A P)$ & $\mathrm{P}$ \\
\hline \multicolumn{3}{|c|}{ Sagittal relationships of the skeletal profile } \\
\hline $\mathrm{N}-\mathrm{Pg} / \mathrm{FH}$ (deg) & 0.46 & 1.000 \\
\hline $\mathrm{N}-\mathrm{A} / \mathrm{Pg}-\mathrm{A}$ (deg) & -1.83 & 0.081 \\
\hline S-N-A (deg) & 0.36 & 1.000 \\
\hline S-N-B (deg) & 1.11 & 0.183 \\
\hline A-N-B (deg) & -0.75 & 0.063 \\
\hline S-N-Pg (deg) & 1.13 & 0.129 \\
\hline A-N-Pg (deg) & -0.84 & 0.141 \\
\hline A to $N-P g(m m)$ & -0.88 & 0.093 \\
\hline N-ANS eff length (mm) & 0.22 & 0.876 \\
\hline $\mathrm{N}-\mathrm{A}$ eff length (mm) & 0.16 & 1.000 \\
\hline N-B eff length (mm) & 1.53 & 0.090 \\
\hline $\mathrm{N}-\mathrm{Pg}$ eff length $(\mathrm{mm})$ & 2.01 & 0.096 \\
\hline \multicolumn{3}{|c|}{ Vertical relationships of the skeletal profile } \\
\hline MPL/SN (deg) & -2.18 & 0.012 \\
\hline MPL/FH (deg) & -2.2 & 0.015 \\
\hline N-M eff height (mm) & 0.5 & 0.774 \\
\hline $\mathrm{N}$-ANS eff height (mm) & 0.16 & 0.615 \\
\hline ANS-Me eff height (mm) & 0.34 & 1.000 \\
\hline \multicolumn{3}{|l|}{ Incisal relationships } \\
\hline UI/LI (deg) & -1.33 & 1.000 \\
\hline UI/LI eff depth (mm) & -0.06 & 1.000 \\
\hline UI/LI eff height (mm) & -0.27 & 0.894 \\
\hline UI/Pal (deg) & 0.74 & 1.000 \\
\hline UI/SN (deg) & 0.96 & 1.000 \\
\hline LI/MPL (deg) & 0.6 & 1.000 \\
\hline LI/FH (deg) & 1.49 & 0.834 \\
\hline iii/A-Pg length (mm) & 0.35 & 0.996 \\
\hline $\mathrm{N}$-uii eff length (mm) & 0.46 & 0.846 \\
\hline $\mathrm{N}$-iii eff length (mm) & 0.52 & 0.381 \\
\hline
\end{tabular}

\begin{tabular}{|c|c|c|}
\hline Variables & $X(M-A P)$ & $\mathrm{P}$ \\
\hline \multicolumn{3}{|c|}{ Sagittal relationships of the soft tissue profile } \\
\hline $\mathrm{N}^{\prime}-\mathrm{Pg}^{\prime} / \mathrm{FH}$ (deg) & 0.47 & 0.780 \\
\hline$N^{\prime}-A^{\prime} / A^{\prime}-P g^{\prime}(d e g)$ & 0.47 & 1.000 \\
\hline$G^{\prime}-A^{\prime} / A^{\prime}-P g g^{\prime}(d e g)$ & -0.16 & 1.000 \\
\hline$N^{\prime}-P^{\prime} / P g^{\prime}-L s(d e g)$ & 1.63 & 0.348 \\
\hline Ls/Ns-Pg'(deg) & 1.2 & 0.279 \\
\hline Li/Ns-Pg' length (mm) & -0.98 & 0.318 \\
\hline Ns-N' eff length (mm) & 0.46 & 0.153 \\
\hline $\mathrm{N}^{\prime}-\mathrm{Sn}$ eff length (mm) & 1.12 & 0.072 \\
\hline $\mathrm{N}^{\prime}-\mathrm{A}^{\prime}$ eff length (mm) & 0.96 & 0.012 \\
\hline $\mathrm{N}^{\prime}$-Ls eff length (mm) & 2.62 & 0.012 \\
\hline $\mathrm{N}^{\prime}$-St(mean) eff length (mm) & 1.54 & 0.009 \\
\hline $\mathrm{N}^{\prime}$-Li eff length (mm) & 0.81 & 1.000 \\
\hline $\mathrm{N}^{\prime}$-B' eff length (mm) & 0.62 & 0.249 \\
\hline $\mathrm{N}^{\prime}-\mathrm{Pg}^{\prime}$ eff length (mm) & 1.12 & 0.405 \\
\hline \multicolumn{3}{|c|}{ Vertical relationships of the soft tissue profile } \\
\hline Sn-Me' eff height & -0.84 & 0.336 \\
\hline Sn-St.mean eff height (mm) & -0.69 & 0.215 \\
\hline Sn-St.sup eff length (mm) & -0.13 & 1.000 \\
\hline St.mean-Me' eff height (mm) & 0.12 & 1.000 \\
\hline St.inf-Me' eff length (mm) & -0.37 & 1.000 \\
\hline St.mean-B' eff length (mm) & -0.47 & 1.000 \\
\hline St.inf-B' eff length (mm) & -0.97 & 0.816 \\
\hline \multicolumn{3}{|l|}{ Soft tissue thickness } \\
\hline Sn-A eff length (mm) & 0.76 & 0.165 \\
\hline Ls-Uifac eff length (mm) & 1.42 & 0.051 \\
\hline Li-Lifac eff length (mm) & -0.32 & 1.000 \\
\hline $\mathrm{Pg}$-Pg eff length (mm) & -0.61 & 0.060 \\
\hline$A^{\prime}-A$ eff length $(\mathrm{mm})$ & 0.85 & 0.048 \\
\hline $\mathrm{B}^{\prime}-\mathrm{B}$ eff length (mm) & 0.02 & 1.000 \\
\hline \multicolumn{3}{|l|}{ Lip morphology } \\
\hline Sn-Ls/FH (deg) & 3.61 & 0.090 \\
\hline Li-B'/FH (deg) & 2.74 & 0.804 \\
\hline$A^{\prime}$-Ls eff length $(\mathrm{mm})$ & 0.28 & 1.000 \\
\hline $\mathrm{B}^{\prime} / \mathrm{Pg}^{\prime}$-Ls length $(\mathrm{mm})$ & -0.52 & 0.201 \\
\hline $\mathrm{Li} / \mathrm{Pg}^{\prime}$-Ls length (mm) & -1.68 & 0.000 \\
\hline
\end{tabular}

The minus symbol indicates that the actual profile value is bigger, While the plus that the actual profile value is smaller. 
Table 2. Mean value differences between manual $(M)$ and computerized $(C)$ surgical prediction $(M-C)$ $(n=18)$.

\begin{tabular}{|c|c|c|c|c|c|}
\hline Variables & $X(M-C)$ & $P$ & Variables & $X(M-C)$ & $\mathrm{P}$ \\
\hline \multicolumn{3}{|c|}{ Sagittal relationships of the skeletal profile } & \multicolumn{3}{|c|}{ Sagittal relationships of the soft tissue profile } \\
\hline $\mathrm{N}-\mathrm{Pg} / \mathrm{FH}$ (deg) & -0.17 & 1.000 & $\mathrm{~N}^{\prime}-\mathrm{Pg}^{\prime} / \mathrm{FH}$ (deg) & -0.58 & 0.372 \\
\hline $\mathrm{N}-\mathrm{A} / \mathrm{Pg}-\mathrm{A}$ (deg) & 0.17 & 1.000 & $N^{\prime}-A^{\prime} / A^{\prime}-P g^{\prime}($ degl & 0.8 & 1.000 \\
\hline S-N-A (deg) & -0.09 & 1.000 & $G^{\prime}-A^{\prime} / A^{\prime}-P g g^{\prime}(d e g)$ & 0.61 & 1.000 \\
\hline S-N-B (deg) & -0.11 & 1.000 & $\mathrm{~N}^{\prime}-\mathrm{Pg}^{\prime} / \mathrm{Pg} \mathrm{g}^{\prime}-\mathrm{Ls}$ (deg) & 1.67 & 0.015 \\
\hline A-N-B (deg) & 0.02 & 1.000 & Ls/Ns-Pg'(deg) & 0.85 & 0.057 \\
\hline S-N-Pg (deg) & -0.16 & 1.000 & $\mathrm{Li} / \mathrm{Ns}-\mathrm{Pg}$ ' length $(\mathrm{mm})$ & 0.74 & 0.434 \\
\hline A-N-Pg (deg) & 0.07 & 1.000 & Ns-N' eff length (mm) & 0.47 & 0.051 \\
\hline A to $N-P g(m m)$ & 0.03 & 1.000 & $N^{\prime}-S n$ eff length (mm) & 0.76 & 0.039 \\
\hline N-ANS eff length (mm) & 0.13 & 1.000 & $\mathrm{~N}^{\prime}$-A' eff length (mm) & -0.07 & 1.000 \\
\hline $\mathrm{N}-\mathrm{A}$ eff length (mm) & -0.09 & 1.000 & $\mathrm{~N}^{\prime}$-Ls eff length (mm) & 1.07 & 0.006 \\
\hline $\mathrm{N}-\mathrm{B}$ eff length (mm) & -0.16 & 1.000 & $\mathrm{~N}^{\prime}-\mathrm{S}$ mean eff length $(\mathrm{mm})$ & 0.53 & 0.690 \\
\hline $\mathrm{N}-\mathrm{Pg}$ eff length (mm) & -0.24 & 1.000 & $N^{\prime}$-Li eff length (mm) & 0.42 & 1.000 \\
\hline \multicolumn{3}{|c|}{ Vertical relationships of the skeletal profile } & $N^{\prime}-B^{\prime}$ eff length (mm) & -0.02 & 1.000 \\
\hline MPL/SN (deg) & 1.05 & 0.420 & $\mathrm{~N}^{\prime}-\mathrm{Pg}$ ' eff length $(\mathrm{mm})$ & -0.91 & 0.471 \\
\hline MPL/FH (deg) & 1.05 & 0.534 & \multicolumn{3}{|c|}{ Vertical relationships of the soft tissue profile } \\
\hline $\mathrm{N}-\mathrm{Me}$ eff height (mm) & 0.94 & 0.012 & Sn-Me' eff height (mm) & 0.14 & 1.000 \\
\hline N-ANS eff height (mm) & 0.24 & 0.273 & Sn-St.mean eff height $(\mathrm{mm})$ & 0.09 & 1.000 \\
\hline ANS-Me eff height $(\mathrm{mm})$ & 0.71 & 0.018 & Sn-St.sup eff length (mm) & -0.22 & 1.000 \\
\hline \multicolumn{3}{|l|}{ Incisal relationships } & St mean-Me' eff height (mm) & 0.05 & 1.000 \\
\hline UI/LI (deg) & -0.69 & 1.000 & St.inf-Me' eff length (mm) & -0.27 & 1.000 \\
\hline UI/LI eff depth (mm) & -0.45 & 0.117 & St.mean-B' eff length (mm) & 0.52 & 0.782 \\
\hline UI/LI eff height (mm) & 0.1 & 1.000 & St.inf-B' eff length $(\mathrm{mm})$ & 0.21 & 1.000 \\
\hline UI/Pal (deg) & -0.51 & 0.900 & \multicolumn{3}{|l|}{ Soft tissue thickness } \\
\hline UI/SN (deg) & -0.5 & 1.000 & Sn-A eff length (mm) & 0.95 & 0.015 \\
\hline LI/MPL (deg) & 0.14 & 1.000 & Ls-Uifac eff length $(\mathrm{mm})$ & 1.09 & 0.006 \\
\hline LI/FH (deg) & -1.2 & 0.612 & Li-Lifac eff length $(\mathrm{mm})$ & 0.53 & 1.000 \\
\hline iii/A-Pg length (mm) & 0.35 & 0.405 & $P g^{\prime}-P g$ eff length $(\mathrm{mm})$ & -0.57 & 0.099 \\
\hline $\mathrm{N}$-uii eff length (mm) & 0.08 & 1.000 & $A^{\prime}-A$ eff length $(\mathrm{mm})$ & 0.12 & 1.000 \\
\hline \multirow[t]{7}{*}{$\mathrm{N}$-iii eff length (mm) } & 0.53 & 0.078 & $B^{\prime}-B$ eff length (mm) & 0.11 & 1.000 \\
\hline & & & \multicolumn{3}{|l|}{ Lip morphology } \\
\hline & & & Sn-Ls/FH (deg) & 1.24 & 0.837 \\
\hline & & & Li-B'/FH (deg) & -5.14 & 0.231 \\
\hline & & & $A^{\prime}$-Ls eff length $(\mathrm{mm})$ & 1.14 & 0.012 \\
\hline & & & $\mathrm{B}^{\prime} / \mathrm{Pg}^{\prime}$-Ls length $(\mathrm{mm})$ & -0.19 & 1.000 \\
\hline & & & $\mathrm{Li} / \mathrm{Pg}^{\prime}$-Ls length $(\mathrm{mm})$ & 0.15 & 1.000 \\
\hline
\end{tabular}

The minus symbol indicates that the computerized value is bigger, while the plus that the computerized value is smaller. 
surgical orthodontic therapy. A number of methods are now available for predicting the outcome of similar cases.

Prediction procedures are based on ratios representing soft tissue profile changes relative to the surgical movement of bony structures. The database for manual and computerized surgical predictions is derived from studies that report either regression equations or mean ratios of soft relative to hard tissue movements. The results of these studies show predictable effects of the skeletal repositioning for the soft tissue face at the chin, labiomental fold and lower lip in mandibular setback osteotomies. $3,4,26,29,30$ The prediction of soft tissue profile changes following orthognathic surgery is not a precise science and treatment predictions are likely, and not accurate outcomes depending on the ratios utilized.

Although the literature is abundant of studies concerning the accuracy of different commercially available computerized prediction programs, ${ }^{21,31-}$ ${ }^{33}$ no relevant studies about the validity of manual prediction methods for mandibular setback osteotomies can be found.

According to the manual prediction method used in this study (overlay method), all upper facial structures, skeletal and soft tissue, remain basically unchanged by the surgical procedure of mandibular setback osteotomy. Correction of mandibular prognathism results in decrease of the inclination and flattening of the upper lip. 3,4,26,29,30,34 Gjorup and Athanasiou ${ }^{26}$ explained that due to the abnormal incisor relationship before mandibular setback surgery the upper lip is kept in a pseudoposition as a form of adaptation and compensation. Achievement of normal incisor relationship after surgery influences the overlying soft tissue and results in decrease of the inclination and flattening of the upper lip. Techalertpaisarm and Kuroda, ${ }^{35}$ utilizing a 3-dimensional computer-graphic demonstration of facial soft tissue changes following correction of mandibular prognathism, found changes in the central upper lip area. Mobarak et al $^{36}$ evaluated long-term soft tissue changes after mandibular setback surgery and found upper lip straightening with concomitant increase of the nasolabial angle; upper lip length was increased $2 \mathrm{~mm}$ approximately. The present study found that the manual prediction shows the upper lip in a more prominent position than its actual post-surgical one.

In this study, upper lip thickness was increased in the manual prediction tracings compared to its actual post-surgical thickness. Chunmaneechote and Friede, ${ }^{34}$ as well as Mobarak et $a^{36}$ found that mandibular setback surgery resulted in decreased upper lip thickness. Gjorup and Athanasiou ${ }^{26}$ indicated operative changes of upper lip thickness and associated them with the initial preoperative thickness of the area.

The mandibular plane inclination was found to be decreased with the manual prediction method used in this study, that is, the mandible showed a greater anterior rotation compared to the actual one-year post-surgical profile. Athanasiou et $\mathrm{al}^{37}$ in a study assessing long-term skeletal stability after surgical correction of mandibular prognathism by vertical ramus osteotomy, showed that during the post-operative period there was a tendency for posterior rotation of the mandibular corpus. The one-year post-operative tracings used in the present study reflect a more stable final condition where this posterior rotation has already occurred, thus explaining the difference between manually predicted and actual profiles. In the present study, the manually predicted profile seems to be more related to the expected mandibular position immediately post-surgery.

The manual prediction method showed that lower lip distance from plane $\mathrm{Pg}^{\prime}$-Ls is smaller, that is, the lower lip was found in a more anterior position than its actual one. Final lower lip position following mandibular setback osteotomies or other orthognathic procedures cannot be easily predicted with accuracy by different prediction methods. Eales et al, ${ }^{39}$ Konstiantos et al,38 Kolokitha et $\mathrm{al}^{21}$ and Csaszar et $\mathrm{al}^{40}$ evaluated the prediction validity of Dentofacial Planner software following orthognathic surgery and concluded that there is great variability in predicting lip position. Lew $^{41}$ and Chunmaneechote and Friede ${ }^{34}$ tested the prediction accuracy of Quick Ceph software and found that simulation of lower lip changes posed certain difficulties. Ahalon et al ${ }^{42}$ compared the two software mentioned above and concluded that both tended to produce errors in predicting lower lip position. They also found a "linear relationship between the prediction error and the surgical change" for the majority of soft tissue landmarks; the greater the surgical movement, 
the greater the prediction error. Jones et al,43 assessing the validity of a computerized prediction system (CASSOS) for treatment planning of class III skeletal deformities, found that the lips were the main area of inaccuracies.

Most of the inaccuracies of the manual prediction method involve upper facial soft tissue variables, which is most likely due to the fact that, according to the overlay method used in this study, upper facial structures remain unchanged after surgery; thus, these structures were directly transferred from the pre-operative tracing to the prediction tracing without taking into consideration changes that occur in the upper lip area.

In addition to factors directly related to the prediction method and its use, certain other factors influence the predictability of soft tissue profile changes following mandibular setback surgery, such as long-term skeletal relapse and amount of surgical movement, ${ }^{36}$ gender ${ }^{34,36}$ etc. It is reported that customization of ratios of soft to hard tissue changes after orthognathic surgery will enhance the accuracy of treatment simulations. ${ }^{34}$

The prediction validity of Dentofacial Planner computerized cephalometric system relative to dentoskeletal and soft tissue profile changes after mandibular setback osteotomy was evaluated and published in a previous study. ${ }^{21}$ Study findings have shown that Dentofacial Planner predictions tended to place the mandible less posteriorly than its actual position and to underestimate the mandibular plane angle, skeletal and soft tissue total anterior facial heights, skeletal lower anterior facial height and upper lip height. The lower lip was predicted by the computerized method to be in a more anterior position as compared to its postoperative actual position.

Comparison between manual and computerized prediction methods

Comparison between manual and computerized prediction methods showed that both methods are measured, except for those related to upper lip posture and thickness. The manual method compared to the computerized method. Upper lip thickness was found to be more increased by the manual method in comparison to the computerized method. just as accurate for all cephalometric variables places the upper lip in a more anterior position

In general, these predictions impose certain limitations since they are based on correlations between cephalometric variables and cannot fully describe a three - dimensional biologic phenomenon. Despite inherent limitations, the manual overlay method conventionally employed for predicting mandibular setback surgery outcome remains a valuable tool that may facilitate communication between specialists and patients.

\section{CONCLUSIONS}

Study results lead to the following conclusions:

1. The manual prediction increases upper lip thickness at point $A$ ( $A^{\prime}-A$ eff length) compared to its actual position.

2. The manual prediction places the mandible less posteriorly than its actual position.

3. The manual prediction places the lower lip more anteriorly than its actual position.

4. The manual prediction increases upper lip thickness at subnasale (Sn-A eff length) and at incisor level (Ls-Uifac eff length) compared to the computerized prediction.

5. The manual prediction places the upper lip in a more anterior position compared to the computerized prediction.

\section{ACKNOWLEDGEMENT}

The author gratefully acknowledges Athanasios E. Athanasiou, Professor and Chairman, Department of Orthodontics, School of Dentistry, Aristotle University of Thessaloniki, Greece, for his significant contribution in guiding, advising and counselling this research project, as well as for providing access to the records used in this study.

\section{REFERENCES}

1. Eckhardt CE, Cunningham SJ. How predictable is orthognathic surgery. Eur J Orthod 2004;26:303-309.

2. Knowles CC. Changes in the profile following surgical reduction of mandibular prognathism. $\mathrm{Br} J$ Plast Surg 1965;18:432-434.

3. Hersey HG, Smith LH. Soft tissue profile change associated with surgical correction of prognathic mandible. $\mathrm{Am} J$ Orthod 1974;65:485-502.

4. Lines PA, Steinhauser WW. Soft tissue changes in relationship to movement of hard structures in orthognathic surgery: a preliminary report. J Oral Surg 1974;32;891896. 
5. Gaggl A, Schultes G, Karcher H. Changes in soft tissue profile after sagittal split ramus osteotomy and retropositioning of the mandible. J Oral Maxillofac Surg 1999;57:542-546.

6. Wolford LM, Hilliard FW, Dugan DJ. Surgical Treatment Objective. A Systematic Approach to the Prediction Tracing. St. Louis: Mosby Year Book, 1985:54-74.

7. McNeil RW, Proffit WR, White RP. Cephalometric prediction of orthognathic surgery. Angle Orthod 1972;42:154-164.

8. Henderson D. The assessment and management of bony deformities of the middle and lower face. Br J Plast Surg 1974;66:378-396.

9. Bench RW, Gugino CF, Hilgers JJ. Bioprogressive therapy: Part 3 - Visual Treatment Objective. J Clin Orthod 1977;11:744-763.

10. Moshiri F, Jung ST, Sclaroff A, Marsh JL, Gay DW. Orthognathic and craniofacial surgical diagnosis and treatment planning: A visual approach. J Clin Orthod 1982; 16:37-59

11. Bhatia SN, Sowray JH. A computer-aided design for orthognathic surgery. Br J Oral Maxillofac Surg 1984;22:237253.

12. Harradine NWT, Burnie DJ. Computerized prediction of the results of orthognathic surgery. J Maxillofac Surg 1985;13:245-249.

13. Walters $H$, Walters $\mathrm{DH}$. Computerised planning of maxillo-facial osteotomies: the program and its clinical applications. Br J Oral Maxillofac Surg 1986;24:178-189.

14. Seeholzer H, Walker R. Kieferorthopaedische und kieferchirurgische Behandlungsplanung mit dem Computer am Beispiel des Dentofacial Planners. Int Quintessenz 1991;42:59-67.

15. Athanasiou AE, Kragskov J. Computerized cephalometric systems. In: Athanasiou AE (ed). Orthodontic Cephalometry. Mosby-Wolfe, London; 1995:231-240.

16. Loh S, Heng JK, Ward-Booth P, Winchester L, McDonald F. A radiographic analysis of computer prediction in conjunction with orthognathic surgery. Int J Oral Maxillofac Surg 2001;30:259-263.

17. McCollum TG. TOMAC: An orthognathic treatment planning system. Part 3. VTO construction in the vertical dimension. J Clin Orthod 2001;35:478-490.

18. Cousley RRT, Grant E, Kindelan JD. The validity of computerized orthognathic predictions. $J$ Orthod 2003;30:149-154.

19. Power G, Breckon J, Sherriff M, McDonald. Dolphin Imaging Software: an analysis of the accuracy of cephalometric dizitization and orthognathic prediction. Int J Oral Maxillofac Surg 2005;34:619-626.

20. Keim RG, Economides JK, Hoffman P, Phillips HW, Scholz
RP. Computers in orthodontics. JCO roundtables. J Clin Orthod 1992;26:539-550.

21. Kolokitha O-E, Athanasiou AE, Tuncay OC. Validity of computerized predictions of dentoskeletal and soft tissue profile changes after mandibular setback and maxillary impaction osteotomies. Int J Adult Orthod Orthognath Surg $1996 ; 11: 137-152$.

22. Wenzel A, Williams S, Ritzau M. Changes in head posture and nasopharyngeal airway following surgical correction of mandibular prognathism. Eur J Orthod 1989;11:37-42.

23. Solow B, Tallgren A. Natural head position in standing subjects. Acta Odontol Scand 1971;29:519-607.

24. Proffit WR. Treatment planning: The search of wisdom In: Proffit WR, White RP (eds) Surgical - Orthodontic Treatment. Mosby Year Book, St. Louis 1991; 142-191.

25. Jensen AC, Sinclair PM, Wolford LM. Soft tissue changes associated with double Jaw surgery. Am J Orthod Dentofac Orthop 1992;101:266-275.

26. Gjorup H, Athanasiou AE. Soft tissue and dentoskeletal profile changes associated with mandibular setback osteotomy. Am J Orthod Dentofac Orthop 1991;100:312-323.

27. Coben SE. Basion Horizontal. An Integrated Concept of Craniofacial Growth and Cephalometric Analysis. Computer Cephalometrics Associated, Jenkintown, Pennsylvania. 1986.

28. Houston WJB. The analysis of error in orthodontic measurements. Am J Orthod 1983;83:382-390.

29. Kajikawa Y. Changes in soft tissue profile after surgical correction of skeletal Class III malocclusion. J Oral Surg 1979;37:167-74.

30. Wilmot DR. Soft tissue profile changes following correction of Class III malocclusions by mandibular surgery. $\mathrm{Br} J$ Orthod 1981;8:175-181.

31. Cousley RRJ, Grant E, Kindelan JD. The validity of computerized orthognathic predictions. $J$ Orthod 2003;30:149-154.

32. Cousley RRJ, Grant E. The accuracy of preoperative orthognathic predictions. $\mathrm{Br} J$ Oral Maxillofac Surg 2004;42:96-104

33. Koh $\mathrm{CH}$, Chew MT. Predictability of soft tissue profile changes following bimaxillary surgery in skeletal class III Chinese patients. J Oral Maxillofac Surg 2004;62:15051509.

34. Chunmaneechote $P$, Friede H. Mandibular setback osteotomy: facial soft tissue behaviour and possibility to improve the accuracy of the soft tissue profile prediction with the use of a computerized cephalometric program: Quick Ceph Image Pro: v. 2.5. Clin Orthod Res 1999;2:8598.

35. Techalertpaisarn P,KurodaT. Three-dimensional computer 
graphic demonstration of facial soft tissue changes in mandibular prognathic patients after mandibular sagittal ramus osteotomy. Int $J$ Adult Orthod Orthognath Surg 1998; 13:217-225.

36. Mobarak KA, Krogstad O, Espeland L, Lyberg T. Factors influencing the predictability of soft tissue profile changes following mandibular setback surgery. Angle Orthod 2001;71:216-227

37. Athanasiou AE, Mavreas D, Toutountzakis N, Ritzau M. Skeletal stability after surgical correction of mandibular prognathism by vertical ramus osteotomy. Eur J Orthod 1992;14:117-124.

38. Konstiantos KA, O'Reilly MT, Close J. The validity of the prediction of soft tissue profile changes after LeFort I osteotomy using the dentofacial planner (computer software). Am J Orthod Dentofac Orthop 1994;105:241-249.

39. Eales EA, Jones ML, Sugar A. The accuracy of a computerized prediction of the soft tissue profile: A study of 25 patients treated by means of the Le Fort I osteotomy. Int J Orthod Orthognath Surg 1994;9:141-152.

40. Csaszar GR, Bruker-Csaszar B, Niederdellmann H. Prediction of soft tissue profiles in orthodontic surgery with Dentofacial Planner. Int J Adult Orthod Orthognath Surg 1999;14:285-290.

41. Lew KKK. The reliability of computerized cephalometric soft tissue prediction following bimaxillary anterior subapical osteotomy. Int J Adult Orthod Orthognath Surg 1992; 7:97-101.

42. Aharon PA, Eisig S, Cisneros GJ. Surgical prediction reliability: A comparison of two computer software systems. Int J Adult Orthod Orthognath Surg 1997;12:65-78.

43. Jones RM, Khambay BS, McHugh S, Ayoub AF. The validity of a computer-assisted simulation system for orthognathic surgery (CASSOS) for planning the surgical correction of class III skeletal deformities: single-jaw versus bimaxillary surgery. Int J Oral Maxillofac Surg 2007;36:900-908. Epub 2007 Jul 13. 